\title{
ГОМОЦИСТЕИН И ЕГО СВЯЗЬ С ИНДЕКСОМ МАССЫ ТЕЛА У ДЕТЕЙ
}

\author{
Куляшова А.В., Михайлова Е.Г., Калабина Е.В., Шевкуленко И.Г.
}

ГБУЗ «СОДКБ им. Н.Н. Ивановой», Самара

ЦЕЛЬ: изучить уровень гомоцистеина в сыворотке крови у детей и его связь с индексом массы тела (ИМТ), липидным профилем и глюкозой плазмы. Методы: 68 детей (в возрасте от 7 до 15 лет) были распределены на группы с нормальным, избыточным весом и ожирением. Оценивали уровень гомоцистеина крови, липидного профиля и глюкозы плазмы. Результаты: из 68 детей 23 (33\%) были с нормальной ИМТ, 19 (29\%) имели избыточный вес и 26 (38\%) страдали ожирением. Гипергомоцистеинемия выявлена у 17 (24,6\%) детей. Ни у одного из детей с нормальным ИМТ гипергомоцистеинемия не наблюдалась. У 7 человек $(37,5 \%)$ в группе с избыточной массой тела и 9 человек (36,5\%) в группе с ожирением

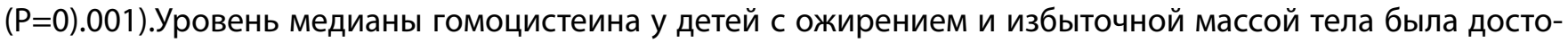
верно выше по сравнению с группой детей с нормальной ИМТ (P=0,001). Была выявлена положительная корреляция между ИМТ и уровнем гомоцистеина. Не было обнаружено достоверной корреляции между липидным профилем и уровнем глюкозы в плазме крови с уровнем гомоцистеина. Уровень витамина В12 и фолиевой кислоты является одним из важных факторов, определяющих уровень гомоцистеина в плазме, и существует отрицательная корреляция между уровнем гомоцистеина в плазме и уровнем витамина В12 и фолиевой кислоты. В нашем исследовании уровни витамина В12 и фолиевой кислоты достоверно не отличались между группой пациентов с нормальной ИМТ и высоким ИМТ.

ВЫводы: уровень гомоцистеина в сыворотке крови значительно выше у детей с избыточной массой тела и ожирением по сравнению с нормальными детьми. 